\title{
Observations and WRF simulations of fog events at the Spanish Northern Plateau
}

\author{
C. Román-Cascón ${ }^{1}$, C. Yagüie $^{1}$, M. Sastre ${ }^{1}$, G. Maqueda ${ }^{2}$, F. Salamanca ${ }^{3}$, and S. Viana ${ }^{4}$ \\ ${ }^{1}$ Dpto. Geofísica y Meteorología, Universidad Complutense de Madrid, Spain \\ ${ }^{2}$ Dpto. Astrofísica y Ciencias de la Atmósfera, Universidad Complutense de Madrid, Spain \\ ${ }^{3}$ Lawrence Berkeley National Laboratory (LBNL), Berkeley, CA, USA \\ ${ }^{4}$ AEMET, Barcelona, Spain
}

Correspondence to: C. Román-Cascón (carlosromancascon@fis.ucm.es)

Received: 11 October 2011 - Revised: 16 January 2012 - Accepted: 17 January 2012 - Published: 28 February 2012

\begin{abstract}
The prediction of fogs is one of the processes not well reproduced by the Numerical Weather Prediction (NWP) models. In particular, the role of turbulence in the formation or dissipation of fogs is one of the physical processed not well understood, and therefore, not well parameterized by the NWP models. Observational analysis of three different periods with fogs at the Spanish Northern Plateau has been carried out. These periods have also been simulated with the Weather Research and Forecasting (WRF) numerical model and their results have been compared to observations. The study includes a comparison of the skill of different planetary boundary layer (PBL) parameterizations, surface layer schemes and a test of the gravitational settling of clouds/fogs droplets option. A statistical analysis of this comparison has been evaluated in order to study differences between the periods and between the various parameterizations used. The model results for each PBL parameterization were different, depending on the studied period, due to differences in the features of each fog. This fact made it difficult to obtain generalized conclusions, but allowed us to determine which parameterization performed better for each case. In general, judging from the models results of liquid water content (LWC), none of the PBL schemes were able to correctly simulate the fogs, being Mellor-Yamada Nakanishi and Niino (MYNN) 2.5 level PBL scheme the best one in most of the cases. This conclusion is also supported by the root mean square error (RMSE) calculated for different meteorological variables.
\end{abstract}

\section{Introduction}

The adverse effects of fog on human activities, especially on transport, are widely known. The physical processes affecting the formation or dissipation of fogs are still not well understood and these processes are not always well parameterized by the Numerical Weather Prediction (NWP) models. The chosen planetary boundary layer (PBL) scheme is very important to obtain appropriate simulations of fogs. Several studies comparing different PBL schemes for the Weather Research and Forecasting (WRF) model have been done in the last years (concerning fogs or not), as Shin and Hong (2011) who did an intercomparison of various PBL parameterizations for a single day, and found differences between unstable and stable conditions. While Welch and Welicki (1986) support the theory that turbulence acts favouring the formation of fog, other authors, such as Roach et al. (1976), established that turbulence favours its dissipa- tion. It seems that there exists a threshold on the relation between turbulence and fog development (Zhou and Ferrier, 2008). Several recent studies have been carried out investigating how NWP models simulate fogs under different conditions. Van der Velde et al. (2010) studied the ability of the High-Resolution Limited-Area Model (HIRLAM) and WRF model to simulate a case of fog under frost conditions and they compared different microphysics and PBL options.

In the present preliminary work, the effect of turbulence on fogs is studied through the use of different PBL parameterizations in order to draw some conclusions and improve fog forecasting. Three different periods with fogs (mainly radiation fogs) have been studied and simulated with the WRFARW (Advanced Research WRF solver) in order to evaluate the ability of the model to simulate these events. For this purpose, three planetary boundary layer (PBL) parameterizations have been compared, as well as three different surface layer (SL) parameterizations. Additionally, an option of 
gravitational settling of cloud/fog droplets has been tested. Differences between simulated and observed values (bias) and RMSE (root mean square error) for different meteorological parameters have been calculated for each period and for each model option.

\section{Data collection}

This study uses data from the Research Centre for the Lower Atmosphere (CIBA in Spanish, $41^{\circ} 49^{\prime} \mathrm{N} 4^{\circ} 56^{\prime} \mathrm{W}$, $840 \mathrm{~m}$ a.s.l.) (Cuxart et al., 2000), located near Valladolid (Spain). It is a place situated over an extensive $\left(800 \mathrm{~km}^{2}\right)$ and homogenous plateau, being a prosperous place for the development of radiation fogs in autumn and winter. The main instrumentation used for this study is installed on two towers $(10$ and $100 \mathrm{~m})$. The $10 \mathrm{~m}$ tower was equipped with two fast-response $(20 \mathrm{~Hz})$ sonic anemometers at 1.5 and $10 \mathrm{~m}$ and with conventional cup anemometers, vanes thermometers and hygrometers at 1.5 and $10 \mathrm{~m}$. The $100 \mathrm{~m}$ tower was equipped with standard anemometers and thermometers at $10,20,35$ and $97 \mathrm{~m}$ and with hygrometers at heights of 10 and $97 \mathrm{~m}$ among other instrumentation. For further information about the CIBA towers, Yagüe et al. (2009) can be consulted. Additionally, visibility information from Valladolid Airport METAR reports was used to support the existence of fogs (human observations made manually). This airport is located $14.5 \mathrm{~km}$ SE from CIBA, but since the terrain is very homogeneous, it was supposed that the conditions in both places were approximately the same. However, sometimes there exists a doubt in the possible local nature of the fog, so for this reason in our study, fogs were considered with relative humidity higher than $95 \%$ at CIBA, which was supported by METAR reports on visibility. Visibilities below $1000 \mathrm{~m}$ are considered fogs by METAR reports; visibilities between 1000 and $5000 \mathrm{~m}$ are considered mists by METAR reports.

\section{WRF-ARW 3.3}

The Weather Research and Forecasting (WRF) Model is a next-generation mesoscale NWP system designed to serve both operational and atmospheric research needs (Skamarock et al., 2008). In this work, WRF-ARW 3.3 version was used. Three turbulent kinetic energy (TKE) PBL parameterizations were chosen: Mellor-Yamada-Janjic (MYJ) (Janjic, 1990), Quasi-Normal Scale Elimination (QNSE) (Sukorianski et al., 2005) and Mellor-Yamada-NakanishiNiino Level 2.5 (MYNN) (Nakanishi and Niino, 2004). These PBL parameterizations have been chosen among others because it has been demonstrated that TKE closure schemes are better at simulating cases dominated by stable conditions, which is what was expected during these periods, at least before the fog onset.
MYJ is the Eta operational scheme. It has a onedimensional prognostic TKE scheme with local vertical mixing. QNSE is an extended version of MYJ based on MYJ PBL code and uses a TKE-prediction option that uses a theory for stably stratified regions (considering anisotropy for diffusivity as well as the effect of internal-gravity waves). It was designed to improve the results in stably stratified conditions. MYNN predicts a more realistic entrainment at the top of the PBL (moreover it forecasts other second order moments besides TKE). It has a new equation for the master mixing length, it parameterizes the buoyancy effects on the pressure covariances and it includes a new condensation physic with respect to the older MYJ (NCEP, 2011).

MYNN allows the use of three different surface layer (SL) parameterizations, which were also compared: MM5 similarity, Eta similarity and MYNN surface layer. MM5 scheme is based on Monin-Obukhov with Carlson-Boland viscous sub-layer and similarity functions from look-up tables. Eta similarity was used in the Eta model and it is based on Monin-Obukhov theory with Zilitinkevich thermal roughness length and standard similarity functions from look-up tables (NCEP, 2011). MYNN surface layer is the Nakanishi and Niino PBL's surface layer scheme and it uses the MoninObukhov theory to calculate the surface layer length scale.

Four two-way nested domains with a horizontal resolution of $27,9,3$ and $1 \mathrm{~km}$, and fifty vertical levels were used (28 levels below $1 \mathrm{~km}$ and 8 levels below $100 \mathrm{~m}$ ). The boundary conditions were taken from NCEP $\left(1^{\circ}\right.$ resolution, each $\left.6 \mathrm{~h}\right)$ and a time step of $90 \mathrm{~s}$ and a spin up of $12 \mathrm{~h}$ were used. Dudhia was the SW radiation scheme chosen, Rapid Radiative Transfer Model (RRTM) the LW radiation and WRF SingleMoment 3-class scheme (WSM3) the microphysics package. A first comparison of three PBL parameterizations was done using MYJ, QNSE and MYNN schemes. Then a comparison of three surface layer (Eta, MM5 and MYNN) parameterizations was done using MYNN PBL scheme. Finally, gravitational settling of cloud/fog droplets option was tested. Since no observed liquid water content (LWC) is available for the studied site, a comparison of the LWC simulated by WRF for the different parameterizations will be shown together with the observed relative humidity.

\section{Observational analysis}

Three different periods of fogs have been studied. Each period is composed of 3 days ( $72 \mathrm{~h}$ ), but the number of fog hours was different for each period. Most of the periods were characterized by favourable synoptic situations for the development of radiation fogs (see Supplement information 1), i.e. high pressures with low pressure gradient and clear skies allowing the nocturnal radiative cooling required to saturate the air. However, in some cases it is difficult to conclude that they are purely radiation fogs. Differences between periods are shown in Table 1, which shows mean values of different 
Table 1. Mean observed values for different parameters for complete periods (3 days) and during strictly fog moments (in brackets).

\begin{tabular}{|c|c|c|c|}
\hline & 10-11-12 November 2009 & 10-11-12 December 2009 & 4-5-6 November 2010 \\
\hline Total hours of fog (72 h) & 13 & 44 & 29 \\
\hline 1.5 m Relative Humidity (\%) & $81.16(96.38)$ & $87.96(96.3)$ & $88.76(97.39)$ \\
\hline $1.5 \mathrm{~m}$ Temperature $\left({ }^{\circ} \mathrm{C}\right)$ & $9.56(6.91)$ & $3.62(1.75)$ & $9.78(6.96)$ \\
\hline $1.5 \mathrm{~m}$ Mixing Ratio $\left(\mathrm{g} \mathrm{kg}^{-1}\right)$ & $6.56(6.58)$ & $4.74(4.59)$ & $7.32(6.71)$ \\
\hline $10 \mathrm{~m}$ Wind Speed $\left(\mathrm{m} \mathrm{s}^{-1}\right)$ & $4.17(3.5)$ & $2.05(1.15)$ & $1.82(1.6)$ \\
\hline Sensible Heat Flux $\left(\mathrm{W} \mathrm{m}^{-2}\right)$ & $10.35(1.36)$ & $12.9(11.92)$ & $20.78(29.35)$ \\
\hline Friction Velocity $\left(\mathrm{m} \mathrm{s}^{-1}\right)$ & $0.76(0.57)$ & $0.25(0.09)$ & $0.14(0.15)$ \\
\hline
\end{tabular}

\section{(a) November 2009}

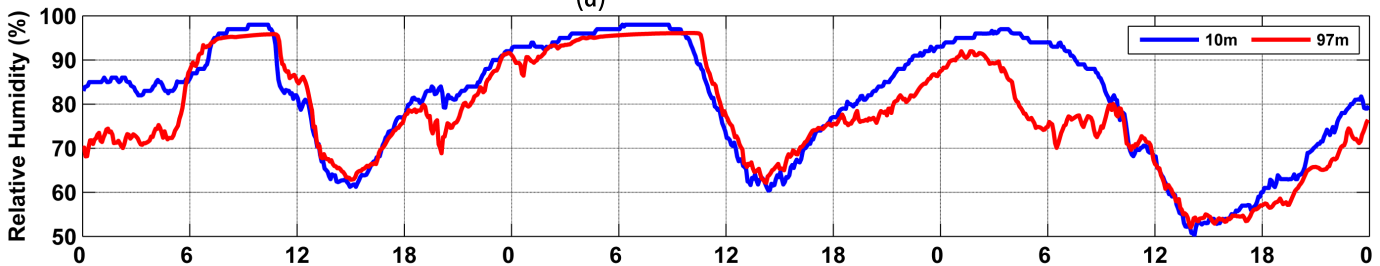

(b)

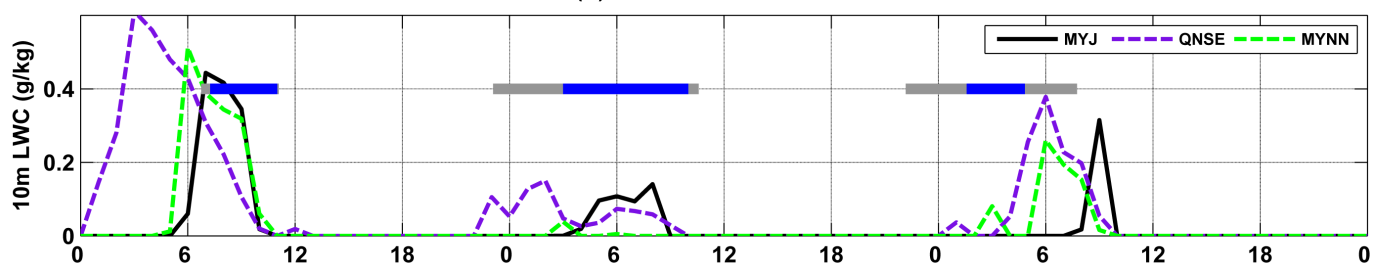

(c)

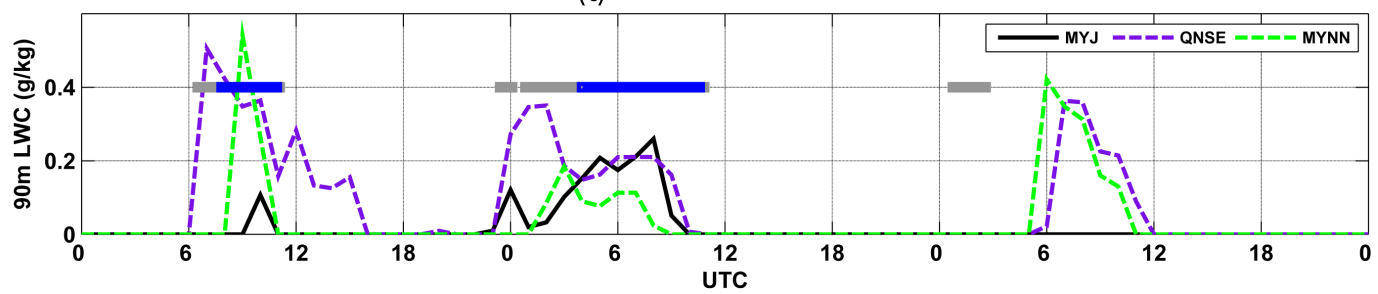

Figure 1. Analysis for 10, 11 and 12 November 2009. (a) Observed relative humidity at $10 \mathrm{~m}$ (blue line) and $97 \mathrm{~m}$ (red line). (b) Simulated LWC at $10 \mathrm{~m}$ using MYJ (black line), QNSE (dashed purple line) and MYNN (dashed green line). Blue and grey rectangles indicate observed relative humidity at $10 \mathrm{~m}$ larger than $95 \%$ and larger than $90 \%$, respectively. (c) Same as (b) for $90 \mathrm{~m}$. Blue and grey rectangles indicate the same as in (b) but for $97 \mathrm{~m}$.

parameters for the periods. Mean values for strictly fog moments are also shown in the same table in brackets. It should be underlined the different degree of turbulence (evaluated from the friction velocity) that is present for the fog moments.

First period corresponds to the period 10-11-12 November 2009. It is composed by a total of $13 \mathrm{~h}$ of fog, characterized by short morning fogs (Fig. 1a). Fogs were present from 07:00 to 10:30 UTC approx. on 10 November. The main feature of this day was the relatively moderate wind speed (not shown), remaining around $2.5 \mathrm{~m} \mathrm{~s}^{-1}$ before the fog onset and increasing from 3 to $4 \mathrm{~m} \mathrm{~s}^{-1}$ when the fog was present. Probably, this increase in wind contributed to the evaporation of the previously condensed dew over the surface during the night and allowed the fog formation. Later, the wind continued increasing and contributed to the fog dissipation. It can be observed how during this day, there is one moment from 06:00 to 07:00 UTC when the relative humidity at $97 \mathrm{~m}$ was greater than at $10 \mathrm{~m}$. The mixing ratio at the height of $97 \mathrm{~m}$ was higher $\left(5.5 \mathrm{~g} \mathrm{~kg}^{-1}\right)$ than those at $10 \mathrm{~m}$ $\left(4 \mathrm{~g} \mathrm{~kg}^{-1}\right)$ (not shown). This increase in mixing ratio at $97 \mathrm{~m}$ was caused by a change in wind direction from SW to $\mathrm{S}$ at 
(a) December 2009

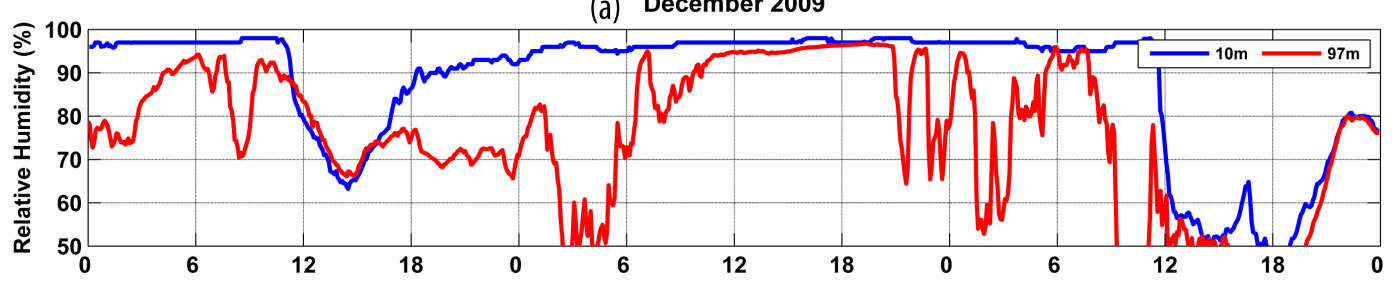

(b)

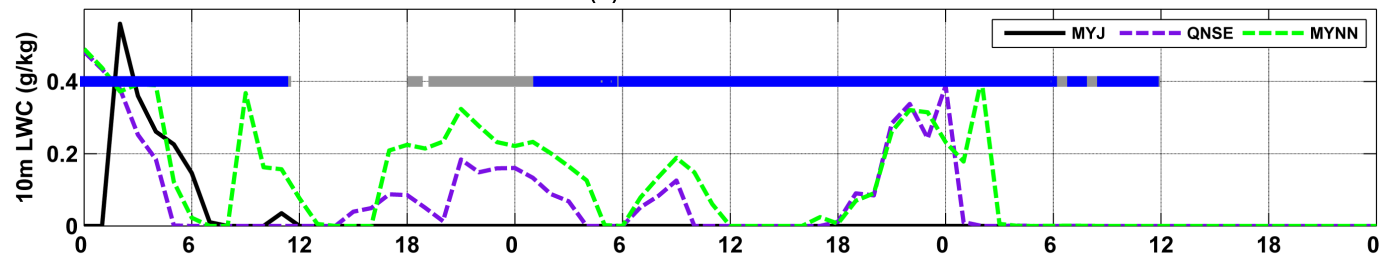

(c)

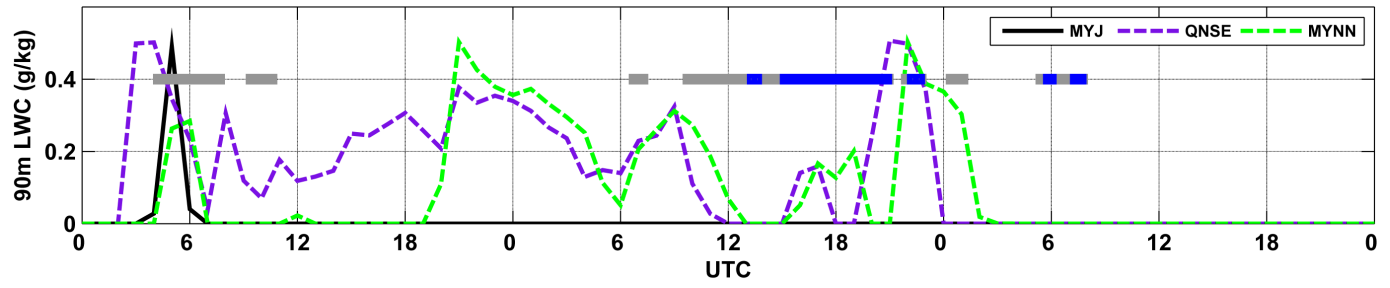

Figure 2. Analysis for 10, 11 and 12 December 2009. (a) Observed relative humidity at $10 \mathrm{~m}$ (blue line) and $97 \mathrm{~m}$ (red line). (b) Simulated LWC at $10 \mathrm{~m}$ using MYJ (black line), QNSE (dashed purple line) and MYNN (dashed green line). Blue and grey rectangles indicate observed relative humidity at $10 \mathrm{~m}$ larger than $95 \%$ and larger than $90 \%$ respectively. (c) Same as (b) for $90 \mathrm{~m}$. Blue and grey rectangles indicate the same as in (b) but for $97 \mathrm{~m}$.

this height during these times (which can represent a source of water vapour at $97 \mathrm{~m}$ ). The second day (day 11), fogs were present from 03:00 to 09:30 UTC; and from 02:00 to 06:00 UTC on day 12, in accordance with relative humidity records. METAR information support this fog schedule except for day 12, when the fog could have a patchy behaviour, being difficult to affirm that a relative humidity higher than $95 \%$ could indicate fog formation on this day. Relative humidity at $97 \mathrm{~m}$ shows how the fog progressed upward and reached this level during days 10 and 11 , but not on day 12 .

The second period corresponds to the period 10-11-12 December 2009. It is composed by a total of $44 \mathrm{~h}$ of fog and can be divided in two fog events (Fig. 2a). The first one is an event of dense fog with visibilities around $100 \mathrm{~m}$ (information from METAR reports, not shown). The onset was around 00:00 UTC on day 10 and the dissipation at 11:00 UTC approximately. The second event was a case of a very persistent fog without dissipation during the daytime, established approximately at 00:00 UTC on day 11 and dissipated the next day (12 December at 12:00 UTC), i.e. remaining for at least $36 \mathrm{~h}$. Relatively low values of friction velocity and wind velocity (not shown) contributed to this persistent fog.
The third case corresponds to the period 4-5-6 November 2010 , with a total of $29 \mathrm{~h}$ of fog. It is a clear case of pure radiation fogs developed during the early hours in the night and dissipated in the afternoon (Fig. 3a). Fogs were established at 05:00 UTC and dissipated at 09:00 UTC on day 4, with a possible progressive transformation into low clouds (decrease in relative humidity at $10 \mathrm{~m}$ and increase at $97 \mathrm{~m}$ ). Day 5 was characterized by fogs formed at 01:00 UTC approximately and dissipated at 12:00 UTC, with a higher relative humidity at $97 \mathrm{~m}$ during the last $3 \mathrm{~h}$ of the event (from 09:00 to 12:00 UTC). On day 6, the fog developed around 23:00 UTC of the previous day and dissipated at 13.30 UTC of day 6, possibly reaching the height of $97 \mathrm{~m}$ from 09:00 to 13:30, as relative humidity records indicate.

\section{WRF Simulation analysis}

The studied periods were simulated with WRF-ARW model using the three PBL parameterizations previously commented on Sect. 3.

Figure $1 \mathrm{~b}$ and $\mathrm{c}$ show simulated liquid water content (LWC) at 10 and $90 \mathrm{~m}$, respectively, using the different PBL parameterizations for the first studied period (November 
(a) November 2010

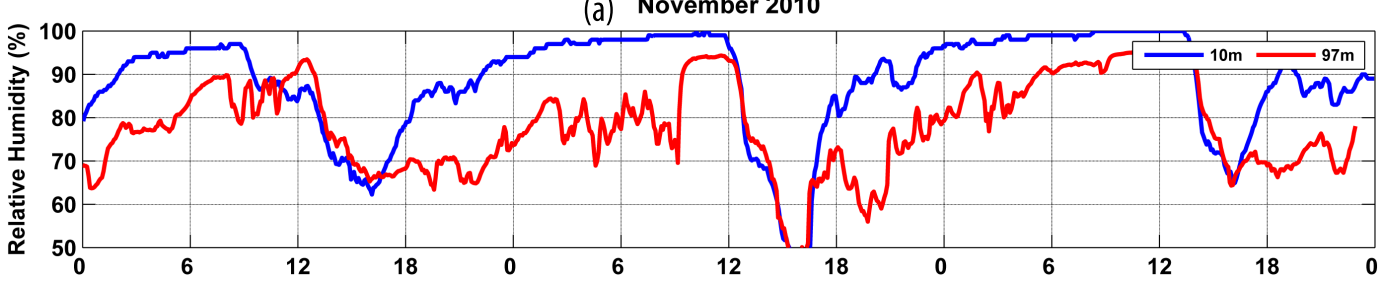

(b)

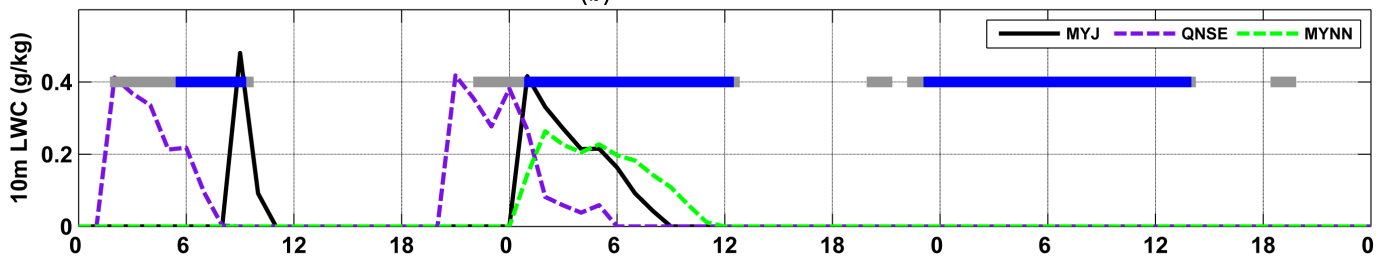

(c)

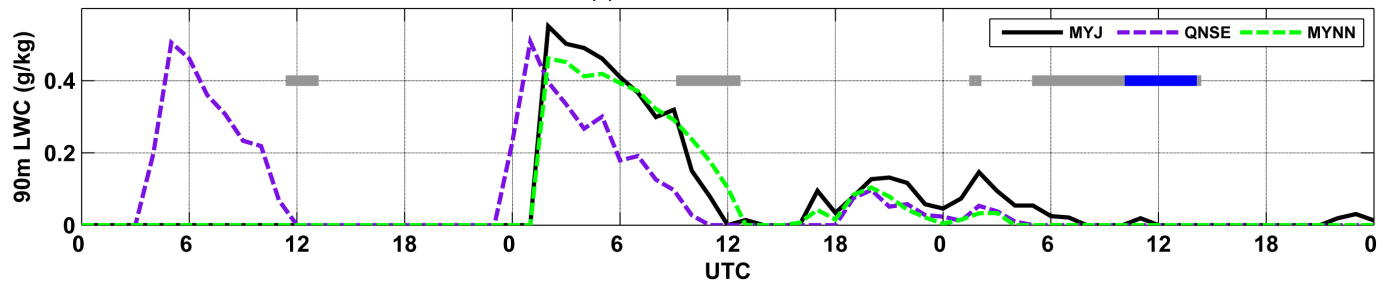

Figure 3. Analysis for 4, 5 and 6 November 2009. (a) Observed relative humidity at $10 \mathrm{~m}$ (blue line) and $97 \mathrm{~m}$ (red line). (b) Simulated LWC at $10 \mathrm{~m}$ using MYJ (black line), QNSE (dashed purple line) and MYNN (dashed green line). Blue and grey rectangles indicate observed relative humidity at $10 \mathrm{~m}$ larger than $95 \%$ and larger than $90 \%$, respectively. (c) Same as (b) for $90 \mathrm{~m}$. Blue and grey rectangles indicate the same as in (b) but for $97 \mathrm{~m}$.

2009). This can be compared with observed relative humidity at 10 and $97 \mathrm{~m}$. For the first day (day 10), the three PBL parameterizations simulated the fog relatively well, but with an earlier dissipation and an earlier formation for QNSE, giving also a wrong transformation of the fog into low clouds (see LWC at $90 \mathrm{~m}$ ). MYJ predicted a correct fog at $10 \mathrm{~m}$ but not at $90 \mathrm{~m}$. MYNN seems to be the best parameterization simulating LWC at 10 and $90 \mathrm{~m}$. For day 11, MYJ was the best PBL scheme simulating the fog at both levels, while for day 12, QNSE and MYNN obtained more realistic results, but slightly delayed on time.

Regarding the second period (December 2009), Fig. 2b and $\mathrm{c}$ shows how MYJ was able to simulate the fog during some hours for the fog event 1 but it was not able to simulate the persistent fog event. MYNN was probably the best PBL scheme simulating the fog during the first event and also during the second fog event, but it was not able to remain the fog during the daytime. QNSE gave a similar behaviour of MYNN. The thickness of the fog was not correctly simulated by any of the parameterizations during this period.

Finally, for the third period (November 2010) (Fig. 3b and c), on day 4 MYJ and QNSE predicted morning fogs, but not MYNN. In any case, the predicted fog was not totally correct on time. QNSE seems to fail in the thickness of the fog, as can be seen looking at LWC simulated at $97 \mathrm{~m}$. Fog on day 5 was relatively well simulated by the three parameterizations; MYNN was the best one, while QNSE and MYJ failed on the onset and dissipation of the fog. Regarding relative humidity at $97 \mathrm{~m}$, all of them overestimate the thickness of the fog. The third day (day 6), none of the PBL parameterizations were able to simulate $\mathrm{LWC}$ at $10 \mathrm{~m}$, while in reality the fog was present for more than $12 \mathrm{~h}$ and reached $97 \mathrm{~m}$ during the last hours of the fog.

A similar comparison but for the different surface layer parameterizations is shown in Supplement information 2. From this comparison is deduced that no important differences can be found using different SL schemes, only small differences.

Additionally, a testing of the Gravitational Settling (GS) option is also shown in Supplement information 2. The effect of using this option was mainly to produce more realistic results in these cases, with less LWC at high levels (it produces a shallower fog and closer to the ground). For November 2009 period, the effect was to produce no LWC at $90 \mathrm{~m}$ on the first day. During days 11 and 12, the effect of using this option did not change significantly the results. For December 2009 , the effect of using the GS option was to obtain more realistic results at $90 \mathrm{~m}$, consequently producing a shallower fog and closer to the ground. For November 2010 period, 
Table 2. RMSE and bias calculated for each period (3 days) and during fog moments (indicated by "fogs") for different parameters and for different PBL parameterizations, MYJ (Mellor-Yamada Janjic), QNSE (Quasi-Normal Scale Elimination) and MYNN Eta (Mellor Yamada Nakanishi and Niino 2.5 level). Lowest values are indicated in bold.

\begin{tabular}{|c|c|c|c|c|c|c|}
\hline \multirow[t]{2}{*}{ 10-11-12 Nov 2009} & \multicolumn{2}{|c|}{ MYJ } & \multicolumn{2}{|c|}{ QNSE } & \multicolumn{2}{|c|}{ MYNN Eta } \\
\hline & RMSE & Bias & RMSE & Bias & RMSE & Bias \\
\hline $2 \mathrm{~m}$ Temperature & 3.03 & -1.51 & 3.24 & -2.13 & 3.03 & -1.69 \\
\hline $10 \mathrm{~m}$ Relative Humidity & 13.00 & 9.60 & 15.33 & 12.85 & 14.21 & 10.74 \\
\hline $10 \mathrm{~m}$ Wind Speed & 2.55 & 0.97 & 2.37 & 0.59 & 2.54 & 1.19 \\
\hline \multicolumn{7}{|l|}{ Nov 2009 (fogs) } \\
\hline $2 \mathrm{~m}$ Temperature & 2.22 & 0.77 & 2.08 & 0.38 & 1.89 & 0.74 \\
\hline 10 m Relative Humidity & 2.55 & 2.09 & 3.02 & 2.88 & 2.80 & 1.92 \\
\hline $10 \mathrm{~m}$ Wind Speed & 3.42 & 2.34 & 3.08 & 2.20 & 3.82 & 2.94 \\
\hline \multirow[t]{2}{*}{ 10-11-12 Dec 2009} & \multicolumn{2}{|c|}{ MYJ } & \multicolumn{2}{|c|}{ QNSE } & \multicolumn{2}{|c|}{ MYNN Eta } \\
\hline & RMSE & Bias & RMSE & Bias & RMSE & Bias \\
\hline $2 \mathrm{~m}$ Temperature & 2.87 & 1.87 & 2.73 & -1.01 & 2.38 & -0.89 \\
\hline 10 m Relative Humidity & 19.03 & -12.38 & 10.49 & 4.78 & 8.08 & 3.94 \\
\hline $10 \mathrm{~m}$ Wind Speed & 1.08 & 0.28 & 0.92 & 0.17 & 0.94 & 0.17 \\
\hline \multicolumn{7}{|l|}{ Dec 2009 (fogs) } \\
\hline $2 \mathrm{~m}$ Temperature & 3.54 & 3.18 & 1.32 & 0.36 & 1.35 & 0.25 \\
\hline 10 m Relative Humidity & 23.61 & -18.93 & 4.50 & 0.11 & 4.34 & 0.78 \\
\hline $10 \mathrm{~m}$ Wind Speed & 0.79 & 0.45 & 0.66 & 0.33 & 0.66 & 0.21 \\
\hline \multirow[t]{2}{*}{ 4-5-6 Nov 2010} & \multicolumn{2}{|c|}{ MYJ } & \multicolumn{2}{|c|}{ QNSE } & \multicolumn{2}{|c|}{ MYNN Eta } \\
\hline & RMSE & Bias & RMSE & Bias & RMSE & Bias \\
\hline $2 \mathrm{~m}$ Temperature & 3.28 & 0.42 & 3.75 & -1.15 & 3.20 & 0.10 \\
\hline 10 m Relative Humidity & 10.08 & 0.20 & 10.61 & 4.56 & 10.91 & 0.08 \\
\hline $10 \mathrm{~m}$ Wind Speed & 1.06 & 0.29 & 1.09 & 0.51 & 1.35 & 0.87 \\
\hline \multicolumn{7}{|l|}{ Nov 2010 (fogs) } \\
\hline $2 \mathrm{~m}$ Temperature & 2.98 & 2.13 & 2.58 & 1.57 & 2.77 & 1.68 \\
\hline 10 m Relative Humidity & 5.85 & -3.62 & 5.08 & -3.05 & 5.91 & -3.29 \\
\hline $10 \mathrm{~m}$ Wind Speed & 1.15 & 0.53 & 0.91 & 0.55 & 1.47 & 1.23 \\
\hline
\end{tabular}

the effect of using the GS option was to obtain better results for LWC for day 6, with a better simulated fog at $10 \mathrm{~m}$ but mistakenly simulated at $90 \mathrm{~m}$.

\section{WRF simulations statistics}

In the previous section it has been shown how, depending on the different fog event analysed, sometimes a PBL parameterization is better than others. In order to have an overall view, a statistical analysis comparing simulated to observational results has been carried out. A total of $216 \mathrm{~h}$ were analyzed and simulated ( $72 \mathrm{~h}$ for each period). The results of these simulations for different parameters were compared with observations. For this purpose, RMSE and bias were calculated for each PBL parameterization. The model produced instant values for each hour, but a comparison with the observed averaged values was done after checking that the temporal variability of the model in the different studied parameters was not very high. Table 2 indicates RMSE and bias for temperature, relative humidity and wind speed for the whole periods. These statistical values have also been calculated only for those moments with determined observed fogs and are labelled in the tables as "fogs". In Supplement information 3, a complete statistical analysis is shown, including variables as friction velocity, mixing ratio and sensible heat flux. Differences between the values for the different periods can be observed.

According to the November 2009 period, lower values for RMSE and bias are observed during fog times, except for wind speed, although it should be taken into account the lower number of fog hours (only $13 \mathrm{~h}$ ). MYNN obtained slightly better results and QNSE for the wind speed prediction. Nevertheless, there were not too many differences between the 3 parameterizations. 
For the December 2009 period, MYJ produced unsatisfactorily results. MYNN was the best scheme with the lowest values of RMSE and bias and QNSE gave the lowest values for wind speed. The model overestimated the temperature during this period because it was not able to predict the persistent fog during the daytime.

For November 2010, QNSE obtained the lowest values for bias and RMSE during fog times. Despite this, the results for the three PBL parameterizations used were quite similar.

During fog moments, all of the parameterizations overestimated the temperature. This could be one of the reasons why the model did not predict the fog. These overestimated temperatures did not allow relative humidity to increase sufficient to produce condensation. In general, these temperature biases were positive during the whole period because the model did not predict the fog, and a higher temperature was simulated during daytime, a consequence of a higher downward short wave radiation at surface than in the reality. These results agree with Shin and Hong (2011), who found how the PBL parameterizations in WRF tended to underestimate the surface cooling rates during nighttimes (in this case before the fog onset).

The predicted wind can be also an important factor affecting the fog forecasting: with positive bias values, the higher wind speed predicted could give an earlier dissipation of fogs.

The first problem is that a comparison done with only $72 \mathrm{~h}$ is not sufficient to obtain reliable results. It has also been deduced that a complete statistics, using the three periods together, cannot be done since the studied periods and their statistical values are different from each other, depending on the period. The fact of using different types of radiation fogs and trying to use them as the same type should affect the results of the simulation with different PBL parameterizations. The evolution and the type of fog are mainly driven by the phase changes of the fog water and its microphysics, radiation budget, advection, turbulence and effects of the terrain (Cuxart and Jiménez, 2012). That is, the relative importance of turbulence over fog would not be the same, depending on the other factors and on the type of the fogs. For instance, it would not be the same in a case of persistent, dense and deep fog as in a case of short, not very dense and shallow fog. A classification of different types of radiation fogs has to be done in order to correctly calculate this type of statistics using different PBL parameterizations. Despite these uncertainties, MYNN scheme seems to be the best PBL parameterization for most cases, with the minimum RMSE values. Also, the use of the gravitational settling option produced slightly better results (see Supplement information 3).

There were well known discrepancies in the formation and dissipation of fogs by MYJ PBL scheme (see Nakanishi and Niino, 2004), and the improvements added to MYNN and QNSE (see Sect. 3) seem to work during some of these cases. Nevertheless, these improvements are not sufficient in some cases, as for the case of persistent fog in December 2009 period and the radiation fog observed on 6 November 2010.

\section{Conclusions}

Three periods with fogs at the Spanish Northern Plateau were analysed and simulated with WRF-ARW model. The features of the fogs were different for each period, and consequently, the results of the simulations depended on the period more than on the option used to simulate, making it difficult to obtain generalized conclusions from this study. Despite this, MYNN obtained slightly better results simulating LWC during fog moments. The surface layer scheme used was not very important in terms of LWC simulated by the model, with only local differences between the different schemes. Additional gravity settling of cloud/fog droplets produced less LWC at high levels, a shallower fog, and it usually served to improve the simulation. The relative importance of the different physical processes (turbulence among them) depends on the features and the type of radiation fogs. A radiation fog classification is needed to compare the differences between observations and simulated values with different PBLs parameterizations. Despite the improvement obtained using MYNN and QNSE parameterizations, it has been demonstrated how they have several uncertainties concerning fog simulations during specific events.

\section{Supplementary material related to this article is available online at: http://www.adv-sci-res.net/8/11/2012/ asr-8-11-2012-supplement.zip.}

Acknowledgements. The authors wish to thank Javier Peláez (CIBA) for his technical support and help as well as J. L. Casanova, Director of the CIBA. We are also very grateful to the editor and two anonymous referees for their constructive suggestions, which helped to improve this paper. This research has been funded by the Spanish Ministry of Science and Innovation (project CGL2009-12797-C03-03). The GR35/10 program (supported by $\mathrm{BSCH}$ and UCM) has also partially financed this work through the Research Group "Micrometeorology and Climate Variability" (No 910437).

Edited by: G.-J. Steeneveld

Reviewed by: two anonymous referees

The publication of this article is sponsored by the European Meteorological Society. 


\section{References}

Cuxart, J. and Jiménez, M. A.: Deep radiation fog in a wide closed valley: Study by numerical physics: its design and verification, Pure Appl. Geophys., doi:10.1007/s00024-011-0365-4, in press, 2012.

Cuxart, J., Yagüe, C., Morales, G., Terradellas, E., Orbe, J., Calvo, J., Fernandez, A. Soler, M. R., Infante, C., Buenestado, P., Espinalt, A., Joergensen, H. E., Rees, J. M., Vilá, J., Redondo, J. M., Cantalapiedra, I. R., and Conangla, L.: Stable Atmospheric Boundary-Layer Experiment in Spain (SABLES 98): A report, Bound.-Lay. Meteorol., 96, 337-370, 2000.

Janjic, Z. A.: The step-mountain coordinate: physics package, Mon. Weather Rev. 118, 1429-1443, 1990.

Nakanishi, M. and Niino, H.: An improved Mellor-Yamada level3 model with condensation physics: its design and verification, Bound.-Lay. Meteorol., 112, 1-31, 2004.

NCEP: Mesoscale \& Microscale Meteorology Division, Weather Research \& Forecasting ARW Version 3 Modeling System User's Guide, 2011.

Roach, W. T., Brown, R., Caughey, S. J., Garland, J. A., and Readings, C. J.: The physics of radiation fog I - a field study, Q. J. Roy. Meteor. Soc., 102, 313-333, 1976.

Shin, H. H. and Hong, S.-Y.: Intercomparison of Planetary Boundary Layer Parameterizations in the WRF Model for a Single Day from CASES-99, Bound.-Lay. Meteorol., 281, 139-261, 2011.
Skamarock, W. C., Klemp, J. B., Dudhia, J., Gill, D. O., Barker, D. M., Duda, M. G., Huang, X. Y., Wang, W., and Powers, J. G.: A description of the advanced research WRF version 3, NCAR Technical note, NCAR/TN-475+STR, 113 pp., 2008.

Sukorianski, S., Galperin, B., and Perov, V.: Application of a new spectral theory of stable stratified turbulence to the atmospheric boundary layer over sea ice, Bound.-Lay. Meteorol., 117, 231257, 2005.

Van Der Velde, I. R., Steeneveld, G. J., Wichers Schreur, B. G. J., and Holtslag, A. A. M.: Modeling and Forecasting the Onset and Duration of Severe Radiation Fog under Frost Conditions, Mon. Weather Rev., 138, 4237-4253, 2010.

Welch, R. M. and Welicki, B. A.: The stratocumulus nature of fog, J. Appl. Meteorol., 25, 101-111, 1986.

Yagüe, C., Sastre, M., Maqueda, G., Viana, S., Ramos, D., Vindel, J. M., and Morales, G.: CIBA2008, an experimental campaign on the atmospheric boundary layer: preliminary nocturnal results, Física de la Tierra, 21, 13-26, available at: http://revistas.ucm. es/fis/02144557/articulos/FITE0909110013A.PDF, 2009.

Zhou, B. and Ferrier, B. S.: Asymptotic Analysis of Equilibrium in Radiation fog, J. Appl. Meteor. Clim., 47, 1704-1722, 2008. 